\title{
A Framework for Classifying and Assessing Sea Level Rise Risk
}

Authors: M. Hauer ${ }^{1,2}$, R.D. Hardy ${ }^{3,4}$, S. Kulp ${ }^{5}$, V. Mueller ${ }^{6,7}$, D. Wrathalls, M. Oppenheimer, ${ }^{8}$ P. Clark $^{8}$

\section{Affiliations:}

${ }^{1}$ Department of Sociology, Florida State University, Tallahassee, FL, USA 32306.

${ }^{2}$ Center for Demography and Population Health, Florida State University, Tallahassee, FL, USA 32306.

${ }^{3}$ School of the Earth, Ocean, \& Environment, University of South Carolina, Columbia, SC, USA 29208.

${ }^{4}$ Department of Geography, University of South Carolina, Columbia, SC, USA 29208.

${ }_{5}$ Climate Central, Princeton, NJ, USA 08542.

${ }^{6}$ School of Politics and Global Studies, Arizona State University, Tempe, AZ, USA 852873902 .

? International Food Policy Research Institute, Washington, DC, USA 20005.

${ }^{8}$ College of Earth, Ocean and Atmospheric Sciences, Oregon State University, Corvallis, OR, USA 97331-5503.

9 Woodrow Wilson School of Public and International Affairs and Department of Geosciences, Princeton University, Princeton, NJ, USA 08544-1013.

*Correspondence to: Mathew E. Hauer, mehauer@,fsu.edu

\begin{abstract}
:
Population risk assessments of sea level rise are key to understanding the impacts of climate change on coastal communities and necessary for adaptation planning. Future sea level rise exposes coastal populations to a spectrum of risk, but assessments often define exposure narrowly, such as areas experiencing permanent inundation only. We reviewed the most common sea level rise exposure assessment methods and identified three widely used spatial definitions of physical exposure risk: mean higher high water, the 100-year floodplain, and the low-elevation coastal zone. Taken individually, each treat risk to sea level rise as binary (affected or not affected), resulting in narrow definitions, homogenizing risk and exposure across space and time. We present a framework that integrates and smooths these classifications under a single continuous metric. To do so, we advance a sophisticated spatiotemporal flood-modeling approach -- expected annual exposure -- based on a probabilistic spatial envelope that unifies spatial extents between the high-tide line and the 10,000-year floodplain. We show that the effects from sea level rise will impact far more people far sooner than previously thought. In particular, our results suggest that single, binary extent assessments either underestimate or overestimate the magnitude of the at-risk populations while also spatially homogenizing the impacts to sea level rise. Our advance on modeling annual exposure provides a more robust and holistic assessment of the populations most at-risk to flooding from sea level rise. This typology can be used to guide new research connecting risk of sea level rise to related adaptation policies and planning.
\end{abstract}

Keywords: Climate change, sea level rise, flood risk, climate adaptation, climate impacts, annual exposure 


\section{Introduction}

Sea level rise accompanying climate change will cause significant and costly impacts in the 21 st century and beyond. Avoiding adverse consequences depends on our ability to undertake accurate risk assessments linked to adaptation and risk management planning ${ }^{1}$. Research has long sought to identify the impact of sea level rise on society ${ }^{2-4}$, with an increasing focus on estimating populations and assets at-risk ${ }^{2,5,6}$. The human population is concentrated in the low elevation coastal zone (LECZ) with more than 600 million people living in coastal areas globally 7 , and despite the apparent and increasing risk of sea level rise, more than 1 billion are forecast to live in the coastal zone by $2060^{5}$.

Scientific assessments of populations at-risk to future sea level rise date back at least four decades and are relatively common in the scientific literature. Their frequency is likely due to the visibility of sea level rise as a climate impact, the clear potential implication of sea level rise on human migration ${ }^{8}$, the growing size of global coastal populations ${ }^{5}$, the relative simplicity of producing at-risk estimates ${ }^{3}$, and the increasing availability of both geophysical and population data from local to global scales ${ }^{7}$. However, the magnitude of the population estimated to be affected is widely divergent across studies. At the global level, the population estimated to be atrisk to sea level rise ranges from a low of 88 million ${ }^{9}$ to a high of 1.4 billion ${ }^{5}$. These wideranging estimates can be attributed to several considerations, including: 1) multiple spatial risk categories that affect estimates of how many people will be impacted by sea level rise, and 2) multiple temporal horizons implied by any given spatial extent that affect estimates of when sea level rise impacts will unfold, in the context of individual and societal responses and scientific uncertainty in projections.

In a systematic review of the literature on population risk to future sea level rise, we identified 46 studies that met our search criteria (See Supplementary Material). Spatial extents in these studies range from mean sea level (narrowest risk category) to the 10,000-year floodplain (broadest risk category). The most common three, ranging from narrowest to broadest include (i) complete inundation or submergence under the future high tide line $(n=20)$, (ii) extreme water levels such as storm surge via the 100-year floodplain $(n=17)$, and (iii) the low-elevation coastal zone (LECZ; $n=11$ ) (Supp. Table 1). Here, we develop a typology based on these most common spatial extents, classify them as Permanent Inundation, Direct Effects, and Indirect Effects, and integrate them within a single, continuous, spatial model of summed annual flood risk.

The modeling choices around spatial extent of exposure to sea level rise imply a temporal horizon for when sea level rise impacts will unfold. These temporal horizons can be forecast as short as 100 years ${ }^{10}$ and as long as 2000 years ${ }^{6}$, pushing sea level rise impacts deep into the future. However, permanent inundation is not the most immediate risk from sea level rise. Regular daily to annual tidal flooding events are likely to be the most disruptive to life in the near term, and related impacts are already occurring in many parts of the world (e.g. coastal erosion ${ }^{11}$, coastal flooding ${ }^{12}$, and saltwater intrusion ${ }^{13}$ ). Yet each of the most common approaches overlooks the spatio-temporal continuity of sea level rise impacts on a coastal landscape. In other words, most previous assessments disregard the total annual flood risk above the high tide line spanning from the relatively frequent nuisance (such as a spring/king tide) to extreme $100+$ year floodplains. Such spatio-temporal discord in assessments raises concerns about the limitations of singular spatial or temporal framings. 
Here we advance a sophisticated flood modeling approach, expected annual exposure (EAE) ${ }^{14-}$

${ }^{16}$, for assessing risk of populations exposed to sea level rise based on a probabilistic spatial envelope. EAE unifies all spatial extents beyond the high-tide to holistically capture integrated, total annual flood risk. In addition, we integrate the EAE into a typology that classifies the most common spatial extents used to quantify populations at-risk to sea level rise and connect our classes to adaptation planning. Our unified typology combines the strengths of previous approaches, which allows for better inter-model comparisons between estimates and, crucially, clarifies their implications for risk to sea level rise. To demonstrate the utility of our typology in practice, we combine a comprehensive flood hazard model with small-area population projections in the United States to characterize sea level rise hazards between 2000 and 2100 under three of the IPCC's Representative Concentration Pathways (RCP 2.6, 4.5, and 8.5) and all five Shared Socioeconomic Pathways.

\section{Sea Level Rise Risk Assessments}

As described above, sea level rise risk assessments generally use three spatial extents: area of complete submergence or inundation via rising mean sea-level or mean higher-high water (MHHW), area within the 100-year floodplain, and the area of the LECZ. Figure 1 summarizes these conceptualizations for examining the impacts of sea level rise.

All three approaches to assessing spatial extent share shortcomings related to three assumptions: 1) an equality of spatial risk, 2) equality of temporal risk, and 3) an equality of hazard exposure. First, these approaches presume an equality of risk within each space, assuming a homogeneous, binary risk profile across heterogeneous terrain. For instance, in a floodplain-based approach such as the 100-year floodplain, all populations and assets in the 100-year floodplain are assumed to have equal flood risk, regardless of whether populations or assets are in 10-, 20- or 50-year floodplains. Second, these approaches presume an equality of temporal risk. For people and assets living within $0.9 \mathrm{~m}$ of the current high tide line, those within $0.1-0.2 \mathrm{~m}$ of the line will experience effects of sea level rise sooner than those between 0.8-0.9 $\mathrm{m}$. Third, these approaches presume an equality of hazard exposure. For populations living in the LECZ, some will be exposed to the direct effects of long term sea level rise such as soil salinization or submergence, while others will only be exposed to hazards exacerbated by sea level rise such as episodic extreme sea levels generated by storm surges and associated livelihood impacts. These three approaches dominate the literature and treat risk to sea level rise as binary (affected or not affected), creating too narrow of a definition of risk that homogenizes different types of risk and exposure across both space and time. Together these assumptions result in oversimplifications of the extent, timing, and type of hazard exposure, which all have implications for sea level rise impacts coastal communities can expect over time and the planning measures that will be necessary to alleviate those impacts.

Taken individually, no approach to characterizing spatial extent is likely to accurately represent the heterogeneity of hazards associated with sea level rise nor quantify the spatial extent or timing of exposure. Taken together, however, these assumptions make integrating the three approaches impractical. One solution to this problem is a unifying spatiotemporal metric that characterizes risk across all spatial extents and at all times, such as an estimate of the probability of annual exposure. To this end, we present a typology of the three most common spatial extents, 
classify these spatio-temporal areas as Permanent Inundation, Direct Effects, and Indirect Effects, and unify them under a common metric: expected annual exposure.

Recurrent tidal flooding or flooding on an annual basis (Direct Effects) is the exposure category where we expect impacts that are most immediate and severe ${ }^{17-19}$. Perigean spring tide events cause regularly recurring water levels well above high tide, and in many coastal areas this causes significant flooding, sometimes referred to as nuisance flooding or recurrent tidal flooding ${ }^{20}$, particularly when these tidal events are supported by significant onshore winds from tropical cyclones or storms. Many coastal areas already experience property damages ${ }^{21}$ or soil salinization ${ }^{22}$ that harms agricultural production.

Eventually, recurrent tidal flooding gives way to permanent inundation and submergence of coastal areas under future high tides. The future high tide line (Permanent Inundation) is the narrowest delineation of exposure to sea level rise (i.e. transition from land to ocean), and commonly implies societal impacts that include permanent loss of settled areas, migration, and community relocation ${ }^{8}$. These areas are threatened by inundation and will ultimately be the most adversely affected locations, but societal losses will occur prior to permanent inundation and are dependent on adaptive measures that may be undertaken in advance. It is important to note that this strict delineation eschews other hazards associated with sea level rise.

Areas located between spatial extents defined as the 100-year floodplain and the LECZ broaden populations exposed to coastal flood risk but carry just the occurrence of risk for an associated sea level rise hazard (such as soil salinization) rather than inundation itself ${ }^{5,23}$. Simply residing within these spatial extents does not guarantee exposure to a sea level rise hazard but does carry increased risk of exposure to an extreme event or extended livelihood impacts (i.e. Indirect Effects). For example, some populations in the lower portion of the 100-year floodplain may experience recurrent tidal flooding, permanent inundation, storm surges, and saltwater intrusion in coming decades, ${ }^{24-27}$ while others will not for centuries or millennia. These broader approaches render any coastal area exposed to sea level rise in nearly any time period which makes it difficult to determine exactly who is exposed to sea level rise and when they are exposed.

\section{A Comprehensive Approach to Sea Level Rise Risk}

To demonstrate how our exposure model works, we employed a small-area demographic projection model based on a published approach ${ }^{28}$ and county-level population projections ${ }^{29}$ that were controlled to the Shared Socioeconomic Pathways (SSP) ${ }^{30}$ allowing a near direct translation of our small-area results to national-level SSPs. We base the small-area demographic projection model on standardized Census Block Group boundaries for the period 1940-2010 for 406 US coastal counties ${ }^{28}$.

\section{Digital Elevation Model}

To classify exposure categories, we employed airborne lidar-derived digital elevation models (DEMs) distributed by NOAA ${ }^{31}$ supplemented with the USGS Northern Gulf of Mexico Topobathymetric DEM ${ }^{32}$ in Louisiana and the USGS National Elevation Dataset ${ }^{33}$ in the small fraction of land not covered by the other sources. These elevation data are vertically referenced 
to NAVD88 and converted to the MHHW datum using NOAA's VDatum grid (version 2.3.5) ${ }^{34}$. Following a bathtub model, we assessed exposed land area using a given water height against the elevation model to generate binary inundation surfaces.

To enforce hydrological connectivity and to avoid the presumption that protected, low-lying areas are disconnected from the ocean by levees or ridges, we further refined the DEMs. First we generated inundation surfaces from $0-10 \mathrm{~m}$ above MHHW, at $0.25 \mathrm{~m}$ increments, denoting the $i^{\prime}$ th such height in this sequence by $h_{i}$, and denoting each such binary surface as ThresholdWaterSurface ${ }_{i}$ (lat, lon). For each pixel in the DEM below 10m, we noted the minimum value of $i$ for which ThresholdWaterSurface ${ }_{i}$ (lat, lon) is 1 (i.e., where its elevation is below $h_{i}$ ), which we stored in a new index surface ThresholdIndexSurface(lat,lon). We then incorporated levee data from the Mid-term Levee Inventory (FEMA/USACE, acquired September 2013) and used connected components analysis to remove isolated regions within each inundation surface, thus generating fully connected binary masks ConnectedWaterSurface ${ }_{i}$ (lat, lon). As before, for each pixel in the DEM below 10m, we found the lowest value of $i$ for which ConnectedWaterSurface ${ }_{i}($ lat, lon), which we again stored in an index surface ConnectedIndexSurface(lat,lon).

We assumed that pixels where ThresholdIndexSurface(lat,lon)= ConnectedIndexSurface (lat,lon) are not isolated, and therefore their elevations in the refined DEM are unchanged. However, locations where ThresholdIndexSurface (lat,lon) < ConnectedIndexSurface'(lat,lon) were isolated. To ensure connectivity when thresholding against new water surfaces, we adjusted such pixels' elevations to equal $h_{\text {Connectedindexsurface }}$ (lat,lon).

\section{Sea Level Rise Projections and Flood Risk Event Probability Surfaces}

To produce an internally consistent model of flooding, given every pixel in the adjusted DEM, and any sea level rise projection, we calculated the annual probability that at least one nearby extreme flood event would exceed each pixels' elevation. Here we used the probabilistic sea level rise projections published previously ${ }^{35}$, which incorporate local non-climatic factors such as isostatic adjustment and human-caused land subsidence, and are closely aligned with recent IPCC findings 36,37 .

We specified our model following previous approaches ${ }^{15,24}$ which hold storm surge constant, fitting the parameters of a generalized Pareto distribution (GPD) to historical heights and frequencies of extreme coastal flood events at NOAA tide stations along the US coastline with at least 30 years of hourly records through 2013. This specification allows us to estimate $P(H \geq$ $E \mid Y=2000$ ), the annual probability of the maximum water height, $H$, exceeding elevation, $E$, in the year 2000 (the baseline year, where sea level rise=0). We expanded a framework described previously ${ }^{15}$ to estimate total annual probability of exceedance of any water height in any year, unconditional to sea-level rise sensitivity to emissions. Published sea level rise projections ${ }^{38}$ are provided as a set of probabilistic distributions, each with 10,000 Monte Carlo samples of sea level rise for each tide-guage station and for each year. Below we denote each sample as the function $S L R_{j}(y)$ for $j \in[1, \ldots, 10000]$. From the law of total probability, we can estimate the annual probability of the maximum water height, $H$, exceeds elevation $E$ in year $Y$ from 


$$
P(H \geq E \mid Y=y) \approx \frac{1}{10000} \sum_{j=1}^{10,000} P\left(\left(H+S L R_{j}(y)\right) \geq E \mid Y=2000\right)
$$

We computed this function under each emissions pathway (RCPs 2.6, 4.5, and 8.5) for each decade (2000-2100), for elevations between 0-10 $\mathrm{m}$ at $0.1 \mathrm{~m}$ increments. We stored these probabilities in lookup tables for efficient queries.

For every pixel in the DEM with elevation E(lat,lon), we determined its closest NOAA tideguage station and used the relevant lookup tables to estimate its annual water height exceedance probability for every sea level rise projection listed above. We stored the results in a large raster database, producing probability surfaces $P(H \geq E$ (lat, lon $) \mid Y=y)$ for all three emissions scenarios and decades along the entire US coastline.

\section{Exposure Computation}

To assess population exposure within a US Census Block Group under any water height (including all exposure approaches described above, viz. MHHW, LECZ, as well as 100-year storm surge adjusted for sea level rise), we generated a connected inundation surface. For the MHHW and LECZ layers, we simply thresholded the adjusted DEM to find pixels below SLR(y) and for $(10+\operatorname{SLR}(\mathrm{y}))$, respectively. For the 100-year storm layer, we thresholded the probability surface to find pixels where $P(H \geq E \mid Y=y)<0.01$. For each block group, we counted the percentage of its pixels on dry land (as defined by the National Wetland Inventory ${ }^{39}$ ) covered by the inundation surface, and multiplied by its total population, as predicted by each SSP. To compute expected annual exposure (EAE), defined as the expected number of people on land below the maximum local storm surge height in a given year ${ }^{15}$, we multiplied the value of each pixel within the probability surface $P(H \geq E($ lat,lon $) \mid Y=y)$ by the block group's (per-pixel) population density and computed the sum.

\section{Results}

We find that in the year 2000, the expected number of people in the United States exposed to an annual flood event is just over $600 \mathrm{~K}$ people, $150 \mathrm{~K}$ people lived below the high-tide line, and 2.4M people lived in the 100-year flood plain (Figure 2). The combination of coastal population growth and sea level rise between 2000 and 2020 has already increased the expected annual exposure of the US coastal population by $60 \%$ (610K to $980 \mathrm{~K})$, increased the US coastal population living below the high-tide line by $60 \%$ (150K to $240 \mathrm{~K})$, and increased the US coastal population living in the 100 -year floodplain by $45 \%(2.4 \mathrm{M}$ to $3.5 \mathrm{M})$, despite just a $25 \%$ growth in the entire coastal population over the same period.

As the century progresses, sea level rise places the US coastal population at increasing flood risk (Figure 2 and Table 1). Under high emissions scenarios (SSP2 and RCP 8.5) between 2020 and 2100 , we project the expected annual exposure to increase five-fold to $5.4 \mathrm{M}$ people $(3.1 \mathrm{M}-$ 
$\left.8.4 \mathrm{M}^{1}\right)$; we project the US coastal population below the high-tide line to increase more than seven-fold to 1.8 million people $(0.4 \mathrm{M}-8.3 \mathrm{M})$; and we project the US coastal population living in the 100-year flood plain to increase three-fold to 10.8 million people $(3.8 \mathrm{M}-26.9 \mathrm{M})$. At the same time, we project the population in the 406 coastal counties to increase by just over $40 \%$ (133M to $190 \mathrm{M})$. This indicates that exposure to coastal flood hazards outpaces any increased exposure due to coastal population growth.

Exposure to sea level rise unfolds unevenly across the US (Figure 3). In the year 2000, just two counties had over $100 \mathrm{~K}$ people in the 100 -year floodplain. However, by 2100 and assuming no adaptation, we project one county (Miami-Dade FL) to contain at least $100 \mathrm{~K}$ people permanently inundated, 13 counties with $100 \mathrm{~K}$ people directly affected, and 24 counties with $100 \mathrm{~K}$ indirectly affected. In every single county and typology category, risk of exposure increases faster than population growth.

For any particular county, it is the combination of the three typology categories (Permanent Inundation, Direct, and Indirect) together that capture the breadth of sea level rise risk. Counties with similar risk profiles along one metric (e.g. Permanent Inundation) may have vastly different risk profiles along the other metrics. For example, despite having $100 \%$ of their populations in the LECZ, Currituck NC and Orange TX exhibit markedly different total risk profiles. Table 2 shows selected county pairs with one or more similar risk metrics. Even if three of the four risk metrics are similar, a fourth metric could still be quite different (eg, McIntosh GA compared to Franklin FL). A risk assessment using only one or two metrics will fail to capture important heterogeneity in sea level rise risk and could lead to maladaptation in decision making.

\section{Discussion}

The three most common approaches to characterizing the populations at-risk to SLR have merits depending on data availability, temporal window analyzed, and amount of anticipated SLR. Nevertheless, the lack of consistency across studies and the tendency to use binary exposure categories relay a confusing and unclear message to the adaptation planning and policy-making community.

Successfully adapting to sea level rise will require a suite of adaptation planning responses that respond to the range of social and environmental variability within and across coastal systems. Adaptation planning must attend to the ways that social difference affects vulnerability under similar exposure levels ${ }^{40-44}$. Achieving equity in adaptation planning ${ }^{45,46}$ requires tackling social difference, specifically how differential exposure affects different social groups, as well as variation in social vulnerability and related adaptive capacities. Moreover, holistic approaches to adaptation planning must also account for the varied range of sea level rise hazards beyond inundation (e.g. soil salinization, coastal erosion, etc.) and the consequent ramifications for socially differentiated populations.

Our typology integrates previous risk models, but it also allows a simultaneous assessment of multiple hazard risks and impacts across the range of spatial extents. For example, the typology

\footnotetext{
${ }^{1}$ Lower estimates use SSP 3 and the $5^{\text {th }}$ percentile projection in RCP 8.5 while upper estimates use SSP5 and the $9^{\text {th }}$ percentile projection from RCP 8.5 unless otherwise noted.
} 
implies that populations within the Permanent Inundation class will experience imminent property loss and daily flooding. Unified under EAE, those inhabiting the zone of Direct Effect class ranging from the 1-year to 10000-year floodplain will experience increasing risk of losses from nuisance flooding, storm surge, saltwater intrusion, soil salinization, etc. (see ${ }^{8}$ for review). To make practical use of our typology, a homeowner within a 100 -year flood plain experiences a $1 \%$ chance of flood occurrence in any given year, but there is a $26 \%$ chance of being flooded during the life of a 30 -year mortgage ${ }^{47}$. This total chance of flooding over the life of a mortgage will only grow as areas in the 50-year become 25-year, 10-year, and 1-year floodplains due to sea level rise. Populations in the Indirect Effect class can prepare for a broader set of socioeconomic impacts to livelihoods due to the tangential effects of flooding extending beyond the water line over a large geographic area. For example, extended effects of flooding might include increasing costs of maintaining vulnerable infrastructure, job losses due to declining coastal industries and/or populations ${ }^{48}$, the extended effects of coastal property devaluation ${ }^{21}$, or climate gentrification ${ }^{49}$. This more holistic spatial envelope allows for reimagining adaptation planning needs along a continuum of risk. It is not just who will be affected, but when, and why they will be affected that must be accounted for in adaptation planning scenarios.

Our unified typology demonstrates how any individual spatial extent approach could either overestimate or underestimate the populations at-risk to sea level rise. The most inclusive methods (i.e., LECZ models) project overly liberal estimates of the populations at risk, while the most exclusive methods (i.e., high tide line models) offer overly conservative estimates of the population at risk. Crucially, as our results indicate, geographic regions that are similar under one or multiple spatial extent approaches can be different under another approach- sometimes vastly different (Table 2). Without a unified approach, however, decision-makers may not realize which of their areas has the greatest proportional change in the population at risk. Such a mis-judgement could have significant long-term ramifications for local populations as adaptation strategies would be misguided. For example, Glynn County, GA and Pasquotank County, NC have populations exposed to permanent inundation, and therefore may have similar short-term adaptation responses for those expecting near-term losses (see Table 2). However, over the coming century, Pasquotank NC has double the population who can expect annual flooding and double who will live in the 100-year floodplain. This suggests that compared to Glynn County GA, decision-makers in Pasquotank County NC will need to prioritize long-term adaptation planning and financing, with an eye toward impacts associated with the Direct Effects class. For federal and state agencies, this type of high-level comparison could inform allocation of national adaptation funding to mitigate the most likely types of impacts. At the local level, it offers decision-makers with limited resources to allocate to mitigating impacts critical details that can be used to inform tradeoffs in the adaptation planning process, such as the magnitude of populations to be affected, and when, how and why they will be affected (i.e., inundated, directly affected, or indirectly affected).

How scientists - and crucially policymakers and planners on the frontlines - conceptualize sea level rise risk will inform the adaptation strategies for mitigating the impacts of sea level rise. Popular adaptation strategies for sea level rise include protection, accommodation, advance, and retreat. Typical responses include shoreline armoring, elevating structures, and relocating buildings further from the encroaching shoreline, respectively. Aside from the equity issues of redistributing risk or prioritizing adaptation of privileged populations near the shoreline ${ }^{40,50}$, the typical adaptation strategies ignore the significant implications to populations and infrastructure 
located beyond the 100-year floodplain, who will nonetheless experience increasing direct and indirect effects over time. Our unified approach highlights limitations in the popular approaches, which to date overemphasize the strategies to alleviate inundation, broadening this important conversation in adaptation planning.

\section{Conclusion}

We have shown that our comprehensive approach to assessing sea level rise risk suggests that in the coming century, there will be five times as many people in the 100-year floodplain compared to those below the future MHHW. Importantly, our typology allows comparable estimates of the at-risk population between the risk categories most commonly described. Crucially, the EAE approach unifies the range of estimates of annual exposure from the 1-year to 10000-year flood plains giving decision-makers a better estimate of the population magnitude predicted to be directly affected by annual flood events. Estimates produced within our typology allow for both a more nuanced understanding of the at-risk population as well as a nearly direct comparison with other previously published estimates that use the high tide line, 100-year flood plain, or LECZ.

In summary, there are three main advantages to unifying sea level rise risk assessment around expected annual exposure (EAE). First, by combining the LECZ, 100-year floodplain, MHHW, and EAE into a single framework, we better describe how possible differential impacts vary across space, overcoming the assumed homogeneous risk profile of each individual approach (the assumption of equality of spatial risk within each geography). Different populations within the coastal zone are thus exposed to differential risk, allowing for more nuanced discussions of what it means to be "at-risk" to sea level rise. Our proposed framework captures this inequality.

Second, each individual approach implies varying temporal windows (the assumption of equality of temporal risk). Permanent Inundation assumes sea level rise exposure only at the moment when areas are permanently submerged. Conversely, the LECZ represents the most inclusive estimate of exposure to sea level rise hazards when sea level rise reaches its apex in approximately two millennia with high emissions. Between these two extremes lies a gradient of risk to multiple hazards associated with the slow, continual rise in water levels. Our typology shifts the temporal windows associated with sea level rise hazards from the deep future into the present. The Direct Effects flooding, represented through the EAE, sums the range of annual exposure probabilities over space under any given RCP, suggesting, at present, nearly 1 million people in the US are annually exposed to flood risk events due to sea level rise, a risk profile that changes over time, unlike other approaches.

Third, each individual approach assumes homogeneity of impacts (the assumption of equality of hazard exposure). Each individual approach identifies populations at-risk based on their membership within each designated risk geography: people are either inside or outside the LECZ; inside or outside the 100-year floodplain; inundated or not inundated. This equality of risk within each chosen spatial extent ignores the variability within the actual hazard space. Those projected to live under the future high tide line are exposed to virtually all sea level rise associated hazards: soil salinization, recurrent tidal flooding, storm surge, livelihood impacts, shoreline erosion, etc. In contrast, those who live at higher elevations within coastal communities might only be exposed to storm surge and indirect livelihood impacts. By unifying the most 
common approaches, our typology captures the unequal distribution of risk to sea level rise impacts and allows us to imagine the scenarios that might unfold along the spectrum of risk. 


\section{Figures and Tables}

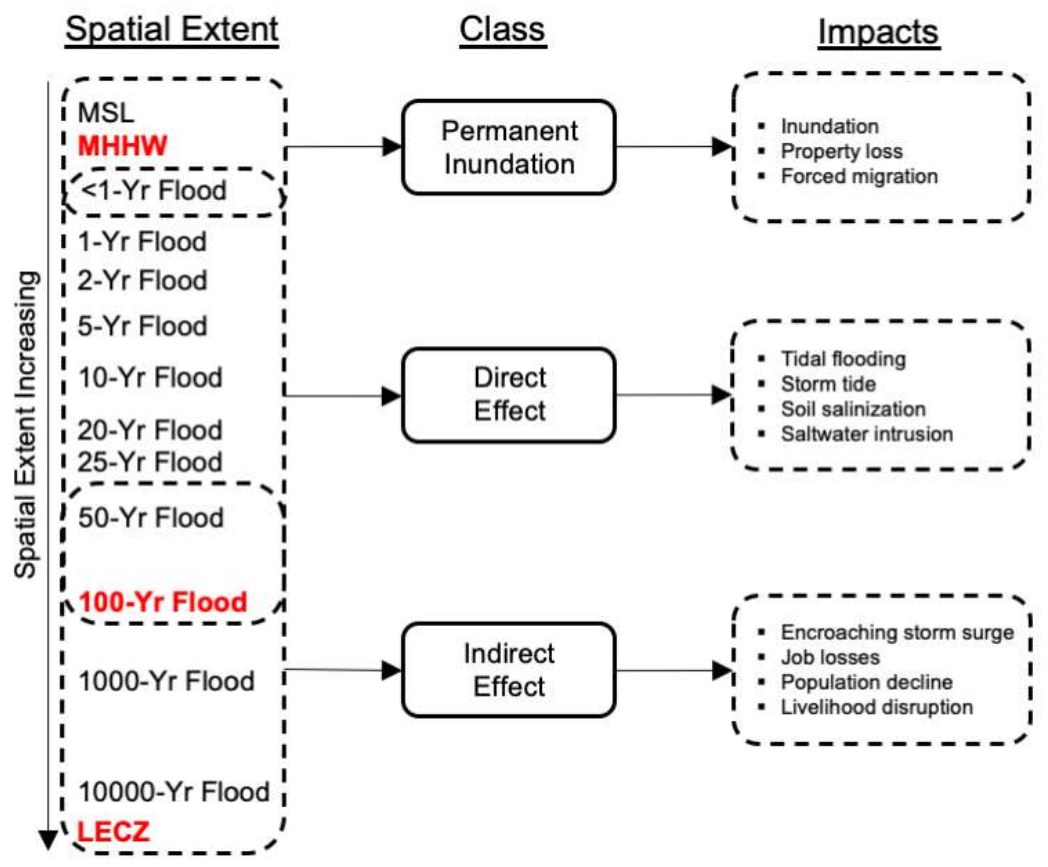

Figure 1. Typology of the most common spatial extents in sea level rise assessment studies. We summarize each spatial extent into three categories. 


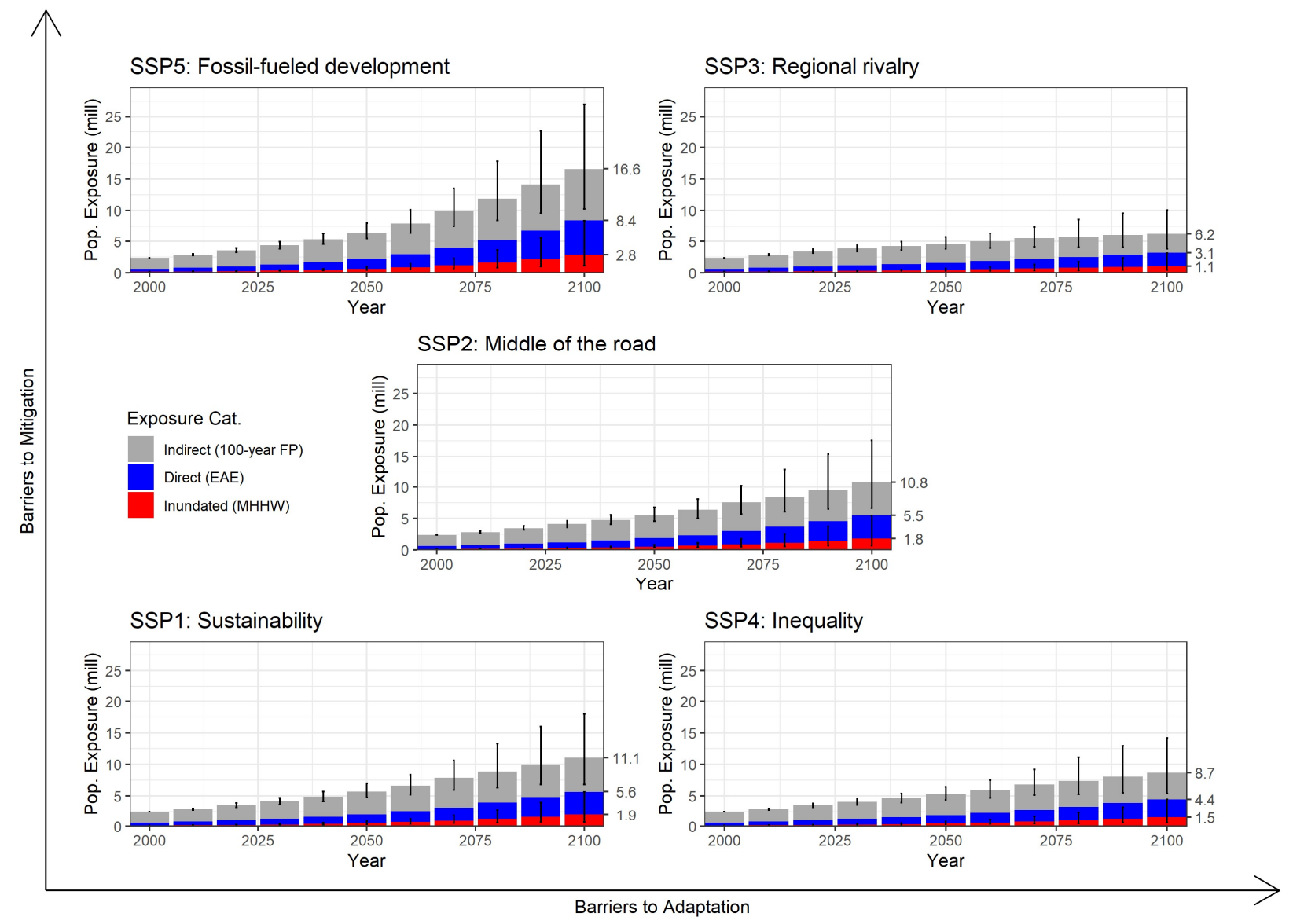

Figure 2. Projections of sea level rise exposure under RCP 8.5 and all five SSPs for 2000 to 2100. Uncertainty reflects the $95^{\text {th }}$ percentile prediction interval. 
a
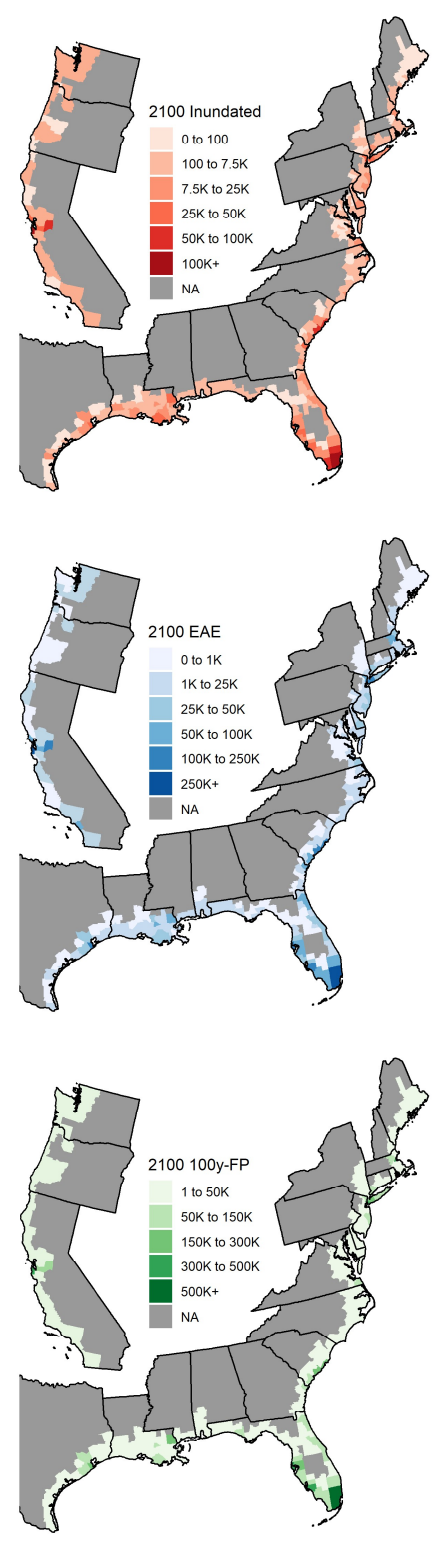
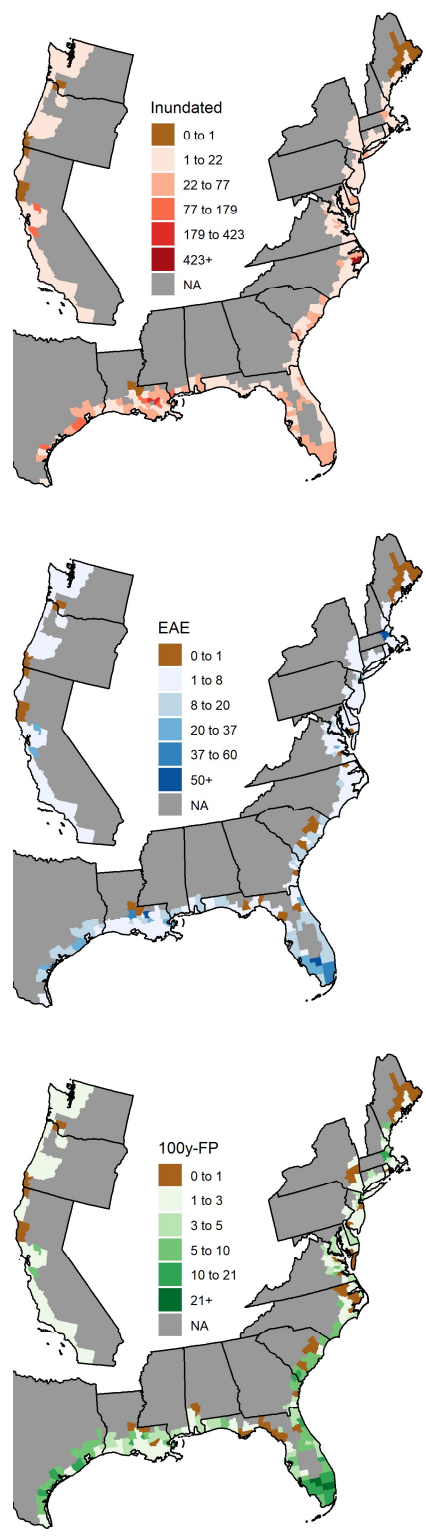

Figure 3. Projected populations Inundated, Expected Annual Flood, and in the 100-year Flood Plain under SSP2 and RCP 8.5. (a) shows the numeric distribution in 2100 and (b) shows the relative change in exposure between 2000 and 2100. 
Figure 4. The percentage of the projected 2100 population under RCP8.5 and SSP2 under the four spatial extents. Here we compare counties with similar risks under different spatial extents to show similarity in one extent does not translate to similar risk under a different spatial extent.

Dare NC Poquoson city VA

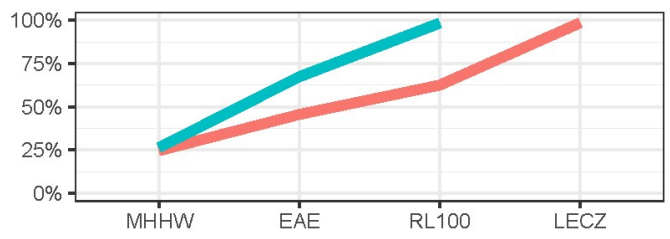

Accomack VA Wakulla FL

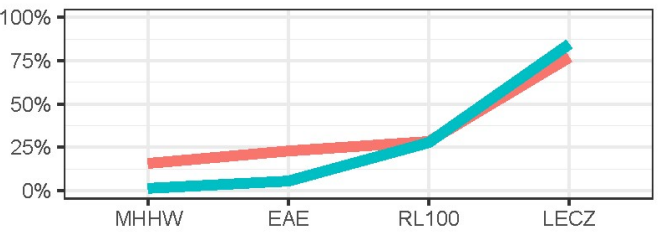

Franklin FL Grays Harbor WA

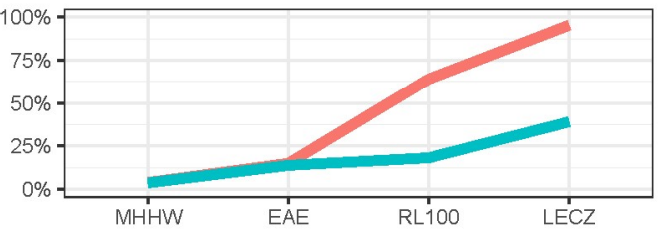

Gulf FL Somerset MD

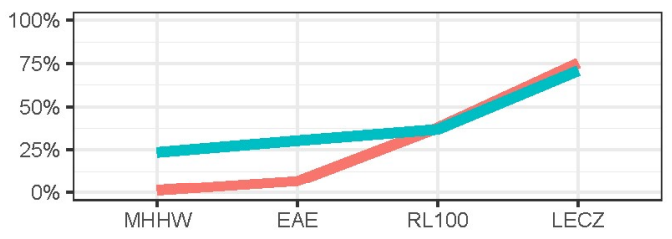

Chatham GA San Mateo CA

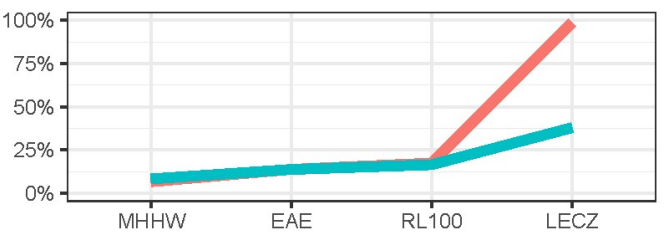

Mathews VA Somerset MD

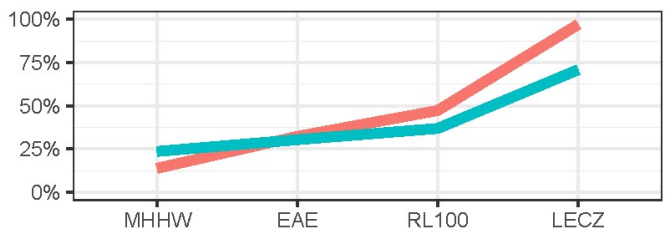

Currituck NC Orange TX

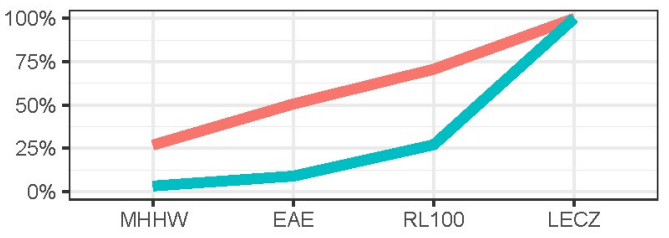

- Hancock MS Norfolk city VA

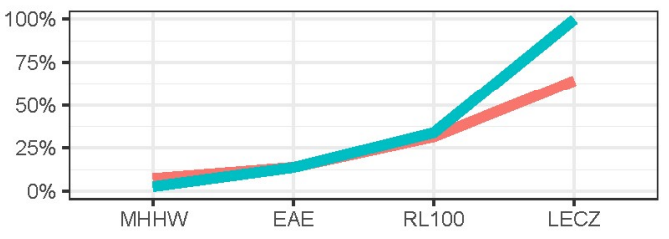

- Glynn GA Pasquotank NC

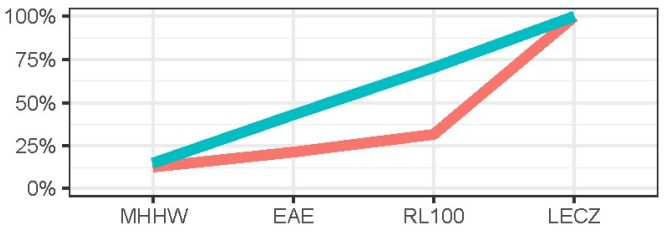

- Franklin FL McIntosh GA

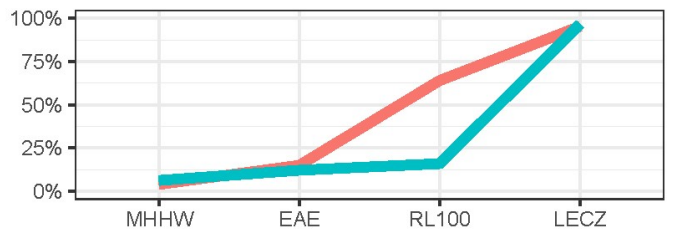


Table 1. Projected populations in all 406 coastal counties exposed in our typology between 2000 and 2100 under SSP2 and RCP8.5 in millions. Uncertainty intervals in parentheses relate to SSP3, $5^{\text {th }}$ percentile and SSP5, $95^{\text {th }}$ percentile. Total refers to the total population in all 406 coastal counties.

\begin{tabular}{|c|c|c|c|c|c|c|}
\hline \multirow[b]{2}{*}{ Year } & & \multirow{2}{*}{$\begin{array}{c}\begin{array}{c}\text { Permanent } \\
\text { Inundation }\end{array} \\
\text { High-Tide Line } \\
\end{array}$} & \multirow{2}{*}{$\begin{array}{c}\text { Direct Effect } \\
\text { EAE }\end{array}$} & \multicolumn{2}{|c|}{ Indirect Effect } & \multirow[b]{2}{*}{ Total } \\
\hline & & & & 100-year Flood Plain & LECZ & \\
\hline & 2000 & 0.15 & 0.61 & 2.36 & 27.64 & 107.15 \\
\hline & 2020 & $0.24(0.21-0.27)$ & 0.98 & $3.46(1.92-2.67)$ & $37.19(36.24-38.16)$ & $133.61(130.84-136.47)$ \\
\hline & 2050 & $0.5(0.29-0.67)$ & 1.88 & $5.5(3.82-8.01)$ & $48.89(40.38-58.27)$ & $165.95(138.18-195.85)$ \\
\hline & 2070 & $0.89(0.36-1.26)$ & 3.01 & $7.56(4.11-13.48)$ & $55.02(39.27-73.99)$ & $181.9(131.42-240.91)$ \\
\hline & 2100 & $1.84(0.4-3.12)$ & 5.49 & $10.79(3.82-26.97)$ & $59.46(33.25-94.38)$ & $190.07(108.8-293.77)$ \\
\hline
\end{tabular}




\section{References}

1. Howden, M. \& Jacobs, K. L. Innovations in assessment and adaptation: building on the US national climate assessment. in The US National Climate Assessment 157-171 (Springer, 2016).

2. Curtis, K. J. \& Schneider, A. Understanding the demographic implications of climate change: estimates of localized population predictions under future scenarios of sea-level rise. Popul. Environ. 33, 28-54 (2011).

3. Schneider, S. H. \& Chen, R. S. Carbon Dioxide Warming and Coastline Flooding: Physical Factors and Climatic Impact. Annu. Rev. Energy 5, 107-140 (1980).

4. Wu, S.-Y., Yarnal, B. \& Fisher, A. Vulnerability of coastal communities to sea-level rise: a case study of Cape May County, New Jersey, USA. Clim. Res. 22, 255-270 (2002).

5. Neumann, B., Vafeidis, A. T., Zimmermann, J. \& Nicholls, R. J. Future Coastal Population Growth and Exposure to Sea-Level Rise and Coastal Flooding - A Global Assessment. PLOS ONE 10, e0118571 (2015).

6. Strauss, B. H., Kulp, S. \& Levermann, A. Carbon choices determine US cities committed to futures below sea level. Proc. Natl. Acad. Sci. 112, 13508-13513 (2015).

7. McGranahan, G., Balk, D. \& Anderson, B. The rising tide: assessing the risks of climate change and human settlements in low elevation coastal zones. Environ. Urban. 19, 17-37 (2007).

8. Hauer, M. E. et al. Sea-level rise and human migration. Nat. Rev. Earth Environ. 1, 28-39 (2020).

9. Desmet, K. et al. Evaluating the Economic Cost of Coastal Flooding. NBER Work. Pap. 24918, (2018).

10. Hinkel, J. et al. Coastal flood damage and adaptation costs under 21 st century sea-level rise. Proc. Natl. Acad. Sci. 111, 3292-3297 (2014).

11. Hinkel, J. et al. A global analysis of erosion of sandy beaches and sea-level rise: An application of DIVA. Glob. Planet. Change 111, 150-158 (2013).

12. Kulp, S. A. \& Strauss, B. H. New elevation data triple estimates of global vulnerability to sea-level rise and coastal flooding. Nat. Commun. 10, 4844 (2019).

13. Chang, S. W., Clement, T. P., Simpson, M. J. \& Lee, K.-K. Does sea-level rise have an impact on saltwater intrusion? Adv. Water Resour. 34, 1283-1291 (2011).

14. Koks, E. E. et al. A global multi-hazard risk analysis of road and railway infrastructure assets. Nat. Commun. 10, 2677 (2019). 
15. Kulp, S. \& Strauss, B. H. Rapid escalation of coastal flood exposure in US municipalities from sea level rise. Clim. Change 142, 477-489 (2017).

16. Rasmussen, D. J., Oppenheimer, M., Kopp, R., Strauss, B. \& Kulp, S. Physical extreme sea level metrics may misrepresent future flood risk. Earth and Space Science Open Archive http://www.essoar.org/doi/10.1002/essoar.10503428.1 (2020) doi:10.1002/essoar.10503428.1.

17. Carbognin, L., Teatini, P., Tomasin, A. \& Tosi, L. Global change and relative sea level rise at Venice: what impact in term of flooding. Clim. Dyn. 35, 1039-1047 (2010).

18. Dahl, K. A., Fitzpatrick, M. F. \& Spanger-Siegfried, E. Sea level rise drives increased tidal flooding frequency at tide gauges along the US East and Gulf Coasts: Projections for 2030 and 2045. PloS One 12, e0170949 (2017).

19. Spanger-Siegfried, E., Fitzpatrick, M. \& Dahl, K. Encroaching tides: How sea level rise and tidal flooding threaten US East and Gulf Coast communities over the next 30 years. (2014).

20. Fennessey, L. A., Hamlett, J. M., Aron, G. \& LaSota, D. Changes in runoff due to stormwater management pond regulations. J. Hydrol. Eng. 6, 317-327 (2001).

21. McAlpine, S. A. \& Porter, J. R. Estimating Recent Local Impacts of Sea-Level Rise on Current Real-Estate Losses: A Housing Market Case Study in Miami-Dade, Florida. Popul. Res. Policy Rev. 37, 871-895 (2018).

22. Chen, J. \& Mueller, V. Coastal Climate Change, Soil Salinity and Human Migration in Bangladesh. Nat. Clim. Change 8, 981-985 (2018).

23. Hallegatte, S. et al. Assessing climate change impacts, sea level rise and storm surge risk in port cities: a case study on Copenhagen. Clim. Change 104, 113-137 (2011).

24. Tebaldi, C., Strauss, B. H. \& Zervas, C. E. Modelling sea level rise impacts on storm surges along US coasts. Environ. Res. Lett. 7, (2012).

25. Woodruff, J. D., Irish, J. L. \& Camargo, S. J. Coastal flooding by tropical cyclones and sealevel rise. Nature 504, 44-52 (2013).

26. Vitousek, S. et al. Doubling of coastal flooding frequency within decades due to sea-level rise. Sci. Rep. 7, 1399 (2017).

27. Sweet, W. V. \& Park, J. From the extreme to the mean: Acceleration and tipping points of coastal inundation from sea level rise. Earths Future 2, 579-600 (2014).

28. Hauer, M. E., Evans, J. M. \& Mishra, D. R. Millions projected to be at risk from sea-level rise in the continental United States. Nat. Clim. Change 6, 691-695 (2016).

29. Hauer, M. E. Population projections for U.S. counties by age, sex, and race controlled to shared socioeconomic pathway. Sci. Data 6, 190005 (2019). 
30. O'Neill, B. C. et al. The roads ahead: Narratives for shared socioeconomic pathways describing world futures in the 21st century. Glob. Environ. Change 42, 169-180 (2017).

31. NOAA. Digital Coast Coastal Lidar. http://coast.noaa.gov/digitalcoast/data/coastallidar (2015).

32. USGS. Coastal National Elevation Database (CoNED) Project - Topobathymetric Digital Elevation Model (TBDEM). https://lta.cr.usgs.gov/coned_tbdem (2014).

33. Gesch, D. et al. The National Elevation Dataset. Photogramm. Eng. Remote Sens. 68, 5-32 (2002).

34. Parker, B., Milbert, D., Hess, K. \& Gill, S. National VDatum - The Implementation of a National Vertical Datum Transformation Database. (2003).

35. Kopp, R. E. et al. Earth's Future Probabilistic 21st and 22nd century sea-level projections at a global network of tide-gauge sites. (2014) doi:10.1002/2014EF000239.

36. Church, J. A. et al. Sea level change. http://drs.nio.org/drs/handle/2264/4605 (2013).

37. Oppenheimer, M. et al. Sea level rise and implications for low lying Islands, coasts and communities. (2019).

38. Kopp, R. E. et al. Probabilistic 21 st and 22nd century sea-level projections at a global network of tide-gauge sites. Earths Future 2, 383-406 (2014).

39. U.S. Fish and Wildlife Service. National Wetlands Inventory. https://www.fws.gov/wetlands/data/data-download.html (2012).

40. Atteridge, A. \& Remling, E. Is adaptation reducing vulnerability or redistributing it? Wiley Interdiscip. Rev. Clim. Change 9, 1-16 (2018).

41. Hardy, R. D., Milligan, R. A. \& Heynen, N. Racial coastal formation: The environmental injustice of colorblind adaptation planning for sea-level rise. Geoforum 87, 62-72 (2017).

42. Marino, E. Adaptation privilege and Voluntary Buyouts: Perspectives on ethnocentrism in sea level rise relocation and retreat policies in the US. Glob. Environ. Change 49, 10-13 (2018).

43. Thomas, K. et al. Explaining differential vulnerability to climate change: A social science review. Wiley Interdiscip. Rev. Clim. Change 10, e565 (2019).

44. Hardy, R. D. \& Hauer, M. E. Social vulnerability projections improve sea-level rise risk assessments. Appl. Geogr. 91, 10-20 (2018).

45. Graham, S., Barnett, J., Fincher, R., Hurlimann, A. \& Mortreux, C. Local values for fairer adaptation to sea-level rise: A typology of residents and their lived values in Lakes Entrance, Australia. Glob. Environ. Change 29, 41-52 (2014). 
46. Graham, S., Barnett, J., Fincher, R., Mortreux, C. \& Hurlimann, A. Towards fair local outcomes in adaptation to sea-level rise. Clim. Change 130, 411-424 (2015).

47. Holmes Jr, R. R. \& Dinicola, K. 100-Year flood-it's all about chance. US Geol. Surv. Gen. Inf. Prod. 106, (2010).

48. Hauer, M. E. Migration induced by sea-level rise could reshape the US population landscape. Nat. Clim. Change 7, 321-325 (2017).

49. Keenan, J. M., Hill, T. \& Gumber, A. Climate gentrification: from theory to empiricism in Miami-Dade County, Florida. Environ. Res. Lett. 13, 054001 (2018).

50. Marino, E. Adaptation privilege and Voluntary Buyouts: Perspectives on ethnocentrism in sea level rise relocation and retreat policies in the US. Glob. Environ. Change 49, 10-13 (2018). 


\section{Supplementary Material}

Sea Level Rise Typology Literature Review

We conducted a systematic review of the literature related to risk assessments of sea level rise. We examined articles through the Web of Science's SCI-Expanded and SSCI indices for the following topics:

$\mathrm{TS}=($ sea-level rise OR sea level rise $)$

AND TS $=($ population $)$

AND TS $=($ risk OR vulnerability OR exposure $)$.

Our search (April 2, 2020) returned 731 results. We filtered the results to include articles of relatively high impact defined subjectively as those with at least four citations per year $(n=152)$. We reviewed the filtered publications for relevancy and selected only those with a spatial risk assessment on human populations or infrastructure in the authors' methods $(n=46)$. For these publications, we identified the spatial extent(s) in their analyses of sea level rise risk and classified them into our typology (see supp. Table 1). 


\begin{tabular}{|c|c|c|c|c|c|c|c|c|c|}
\hline Source & $\begin{array}{l}\text { Average } \\
\text { Cites/Year }\end{array}$ & High Tide & $<1$-yr Flood & 1-Yr Flood & 10-Yr Flood & 100-Yr Flood & 1000-Yr Flood & LECZ & Other Extents \\
\hline Hallegatte et al. (2013) & 76.5 & & & 1 & & 1 & & & \\
\hline McGranahan et al. (2007) & 69.93 & & & & & & & 1 & \\
\hline Neumann et al. (2015) & 60 & & & & & 1 & & 1 & \\
\hline Hinkel et al. (2014) & 47.57 & & & 1 & & 1 & & & \\
\hline Small and Nicholls (2003) & 34.11 & & & & & & & & Near coastal zone \\
\hline Nicholls et al. (2011) & 27.7 & & 1 & 1 & & & & & \\
\hline Hanson et al. (2011) & 26.2 & 1 & & & & 1 & & & \\
\hline Ericson et al. (2006) & 24.13 & & & & & & & & Mean sea level \\
\hline Hauer et al. (2016) & 21.4 & 1 & & & & & & & \\
\hline Jones and O'Neill (2016) & 21.2 & & & & & & & 1 & \\
\hline Nicholls (2004) & 19.76 & & & 1 & & & 1 & & \\
\hline Nicholls et al. (1999) & 18.68 & & & 1 & 1 & 1 & 1 & & \\
\hline Koks et al. (2015) & 18.17 & & & & & & & & 10000-yr flood \\
\hline Muis et al. (2015) & 12.83 & & & & 1 & 1 & 1 & & \\
\hline Tol (2002) & 12.05 & 1 & & & & & & & \\
\hline Nicholls and Tol (2006) & 11.53 & & & 1 & & & 1 & & \\
\hline Hauer (2017) & 9.5 & 1 & & & & & & & \\
\hline Wu et al. (2002) & 9.16 & & & & & & & & Index-based approach \\
\hline Kummu et al. (2016) & 8.4 & & & & & & & 1 & \\
\hline de Moel et al. (2011) & 8.1 & & & & & & & & Levee-breach scenarios \\
\hline Kleinosky et al. (2007) & 7.93 & & & & & 1 & & & \\
\hline Frazier et al. (2010) & 7.36 & & & & & 1 & & & \\
\hline Silva et al. (2014) & 7.29 & & & & & & & 1 & \\
\hline Emrich and Cutter (2011) & 6.7 & 1 & & & & 1 & & & \\
\hline Yin et al. (2012) & 6 & & & & & & & & Mean sea level \\
\hline Dasgupta et al. (2011) & 5.5 & 1 & & & & 1 & & & \\
\hline Barnard et al. (2019) & 5.5 & 1 & 1 & & & 1 & & & 20-yr floods; "average daily conditions" flooding; $5 \mathrm{~m}$ \\
\hline Lichter et al. (2011) & 5.2 & & & & & & & 1 & \\
\hline Martinich et al. (2013) & 5.13 & 1 & & & & & & & \\
\hline Wetzel et al. (2012) & 5.11 & 1 & & & & & & 1 & \\
\hline Gornitz et al. (2001) & 4.85 & & & & 1 & 1 & & & $2,5,25$, and 50 -yr floods \\
\hline Murali et al. (2013) & 4.75 & 1 & & & & & & & \\
\hline
\end{tabular}




\begin{tabular}{|c|c|c|c|c|c|c|c|c|c|}
\hline Source & $\begin{array}{l}\text { Average } \\
\text { Cites/Year }\end{array}$ & High Tide & $<1-y r$ Flood & 1-Yr Flood & 10-Yr Flood & 100-Yr Flood & 1000-Yr Flood & LECZ & Other Extents \\
\hline Anderson et al. (2017) & 4.75 & 1 & & & & & & & \\
\hline Brown et al. (2018) & 4.67 & & & & & 1 & & & \\
\hline Felsenstein et al. (2014) & 4.57 & 1 & & & & 1 & & 1 & \\
\hline Hardy et al. (2017) & 4.5 & 1 & & & & & & & \\
\hline Mimura (1999) & 4.32 & 1 & & & & & & & \\
\hline Curtis and Schneider (2011) & 4.3 & 1 & & & & & & 1 & \\
\hline Dasgupta et al. (2014) & 4.29 & & & & 1 & & & & \\
\hline Paprotny and Terefenko (2017) & 4.25 & 1 & & & & & 1 & & \\
\hline Lichter and Felsenstein (2012) & 4.11 & 1 & 1 & & & 1 & & 1 & 50-yr floods; tsunami events \\
\hline Hardy and Hauer (2018) & 4 & 1 & & & & & & & \\
\hline Xian et al. (2018) & 4 & & & 1 & & 1 & & & \\
\hline Mavromatidi et al. (2018) & 4 & 1 & & & & & & & \\
\hline Benassai et al. (2015) & 4 & & & & & & & 1 & \\
\hline Reguero et al. (2015) & 4 & 1 & & & & 1 & & & El Nino event \\
\hline TOTAL & NA & 20 & 3 & 7 & 4 & 17 & 5 & 11 & \\
\hline
\end{tabular}

